\title{
PREPARATION, CHARACTERIZATION AND ANTIOXIDANT ACTIVITY OF XANTHONE-LOADED MAKING (HODGSONIA HETEROCLITA) MICROEMULSIONS
}

\author{
SUNEE CHANSAKAOW, PANEE SIRISA-ARD, RUTTIROS KHONKARN* \\ Department of Pharmaceutical Sciences, Faculty of Pharmacy, Chiang Mai University, Chiang Mai, Thailand \\ Email: pharrutty@gmail.com
}

Received: 14 Dec 2016 Revised and Accepted: 30 Jan 2017

\begin{abstract}
Objective: The aim of this study was to incorporate xanthone into Making (Hodgsonia heteroclita) microemulsions and to evaluate the antioxidant activity of the formulations.

Methods: Making oil was obtained from the seed of Hodgsonia heteroclite by a screw press machine. The solubility of xanthone in various oils, surfactants, and co-surfactants was investigated. Stable Making microemulsion and microemulsion-based gel were simultaneously loaded with xanthone. Finally, an in vitro xanthone release study was carried out and antioxidant activity was determined.

Results: The optimal formulations of the Making microemulsion consisted of Making oil, capryol 90, tween 80, propylene glycol, and water. The average droplet size of xanthone-loaded Making microemulsion was around 110-130 nm. It was found that the stability of the xanthone-loaded Making microemulsion-based gel was higher than the xanthone-loaded Making microemulsion. Besides, the release of xanthone from the Making microemulsion-based gel was lower than that of the Making microemulsion. Moreover, it was found that the antioxidant activity of both xanthoneloaded Making microemulsion (TEAC and EC values of $9.8 \mathrm{mmol} / \mathrm{mg}$ and $14.8 \mathrm{mmol} / \mathrm{mg}$, respectively) and microemulsion-based gel (TEAC and EC values of $9.4 \mathrm{mmol} / \mathrm{mg}$ and $18.5 \mathrm{mmol} / \mathrm{mg}$, respectively) remained high even after extended storage conditions.
\end{abstract}

Conclusion: It was concluded that Making oil is an attractive material to deliver xanthone in pharmaceutical applications.

Keywords: Making oil, Xanthone, Microemulsion, Antioxidant activity

(C) 2016 The Authors. Published by Innovare Academic Sciences Pvt Ltd. This is an open access article under the CC BY license (http://creativecommons.org/licenses/by/4.0/) DOI: http://dx.doi.org/10.22159/ijpps.2017v9i3.16584

\section{INTRODUCTION}

The extract from the fruit rind of mangosteen (Garcinia mangostana) which belongs to family Guttiferae, is popularly added in cosmetics and pharmaceutical products for various effects due to the antioxidant, anti-inflammatory, and antimicrobial properties of the extract [1-3]. The bioactive components found in the extract are tannins and xanthones, mainly $\alpha$-mangostin [4-7]. However, applications of xanthone are still limited because of its poor aqueous solubility $[8,9]$

Microemulsions are attractive drug delivery systems because of their advantage in increasing drug solubility and thermodynamical stability, in addition to ease of preparation $[10,11]$. This transparent and stable nano-sized system is spontaneously formed when a certain amount of oil, water, surfactant, and co-surfactant are mixed. Moreover, it has been found that transdermal permeability improves when microemulsions are used as topical delivery vehicles [12]. However, the low viscosity of microemulsions makes them inconvenient for topical application. Gelling of microemulsions using bioadhesive agents can increase the viscosity of this formulation as well as enhance the resident time on skin or mucous membranes.

Making (Hodgsonia heteroclita subsp. indochinensis), a rare and endangered species, is a member of the family Cucurbitaceae [1314]. Various parts-such as leaves, stem, pulp, and seeds-have been used as medicine by following indigenous wisdom. A high content of a fixed oil is found in their seeds. The fatty acids in Making seed oil mainly consist of linoleic acid and oleic acid [14]. Linoleic acid and oleic acid can be used as emollients in skincare to maintain the high moisture content and increase the elasticity of skin. Additionally, Making oil exhibits antioxidant activity, with $\mathrm{IC}_{50}=2.48 \pm 0.20$ $\mathrm{mg} / \mathrm{ml}$. The properties of Making oil, therefore, make it suitable as a raw material for the pharmaceutical industry. The aims of this study were to develop and characterize stable microemulsion and microemulsion-based gel containing Making oil to effectively improve the solubility and to maintain the antioxidant activity of xanthone.

\section{MATERIALS AND METHODS}

\section{Materials}

Trolox was purchased from Aldrich Chemical Company (Steinheim, Germany). 2,4,6-Tri(2-pyridyl)-S-triazine (TPTZ), 2,2'-azinobis-(3ethylbenzothiazoline-6-sulfonic acid) diammonium salt (ABTS), ferrous sulfate $\left(\mathrm{FeSO}_{4} \cdot 7 \mathrm{H}_{2} \mathrm{O}\right)$, ferric chloride $\left(\mathrm{FeCl}_{3} \cdot 6 \mathrm{H}_{2} \mathrm{O}\right)$, potassium persulfate, and sodium carbonate were obtained from SigmaAldrich (St. Louis, MO, USA). Other chemicals and solvents were of AR grade or equivalent.

\section{Sample preparation}

The fruits of Making was collected from Chiang Mai, Thailand during August-September, 2014. The samples were identified by a taxonomist, and voucher specimens (voucher no. K. Rapeeporn 098) were deposited at the herbarium of the botanical garden organization, Mae Rim, Chiang Mai University, Thailand. The oil-rich cotyledons were extracted using a screw press machine to obtain the Making oil ( $\%$ yield $=54 \%$ of the dried kernel). On the other hand, xanthone was extracted from the fruit rind of mangosteen (purchased from the herbal drug store in Chiang Mai), as described by Asai et al. [15]. Standardization of xanthone was performed by HPLC. Xanthone is the main content of $\alpha$-mangostin (around $72 \%$ ) as shown in fig. 1. 


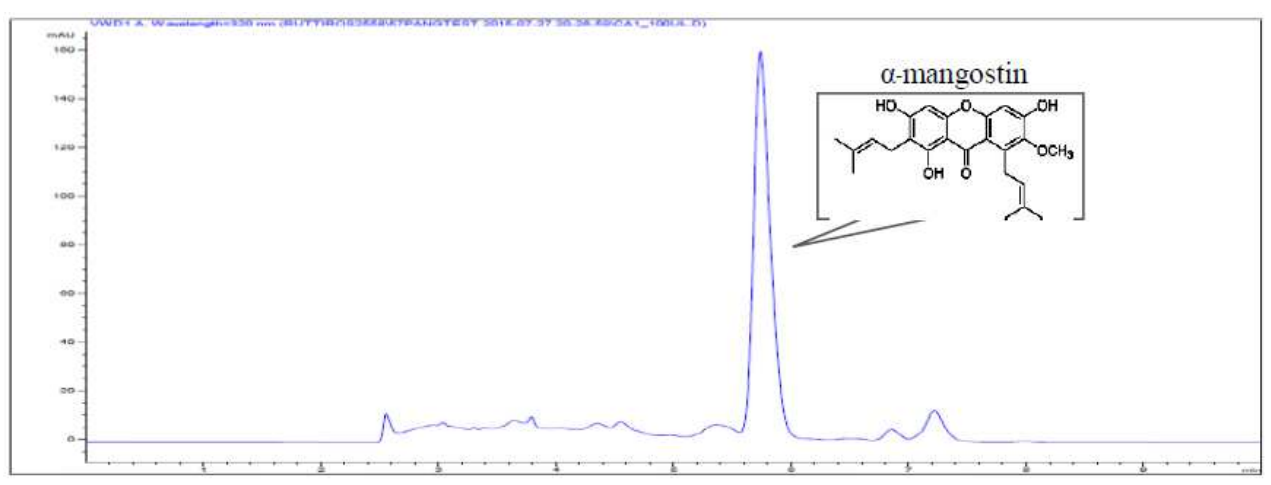

Fig. 1: The HPLC profile of xanthone

\section{Making oil analysis}

The fatty acid profile of Making oil was analyzed by gas chromatography (GC). The fatty acids in the Making seed oil mainly consisted of linoleic acid and oleic acid at 47.01 g/100 g and 14.92 $\mathrm{g} / 100 \mathrm{~g}$, respectively.

\section{Solubility test of xanthone}

The solubility of xanthone in various oils, surfactants, and cosurfactants was assessed by adding an excess amount of xanthone to $2 \mathrm{ml}$ of tested vehicles including oils, surfactants, and co-surfactants as described previously [16]. The mixture was stirred for $2 \mathrm{~d}$ at room temperature. The equilibrated samples were then filtered through a $0.45-\mu \mathrm{m}$ filter to remove the precipitated xanthone. The supernatant was then diluted with methanol and analyzed by high performance liquid chromatography.

\section{High performance liquid chromatography (HPLC) analysis}

The HPLC analysis was performed using a Hewlett Packard (hp1100) with a UV-Visible detector. A reverse phase (C-18) column $(4.6 \mathrm{~mm} \times$ $250 \mathrm{~mm}, 5 \mu \mathrm{m}$ particle size, SB-C18, Hypersil@) with an elution solvent of $100 \%$ acetonitrile was used. The injection volume was $100 \mu \mathrm{l}$ and the flow rate was $1 \mathrm{ml} / \mathrm{min}$ at ambient temperature. The retention time (Rt) was monitored at $320 \mathrm{~nm}$.

\section{Preparation of xanthone-loaded microemulsion and xanthone- loaded microemulsion-based gel}

Pseudo-ternary phase diagrams were constructed by the simple titration method at room temperature according to the solubility of xanthone. Five pseudo-ternary phase diagrams were obtained with various weight ratios of the mixture of oil as well as the mixture of the surfactant and the co-surfactant (Smix). For each of the pseudo-ternary phase diagrams, mixtures of oil and Smix (weight ratios of 10:0, 9:1, 8:2, 7:3, 6:4, 5:5, 4:6, $3: 7,2: 8,1: 9$, and 10:0) were prepared. After that, water was gently added to this mixture with controlled stirring. The phase boundary at which the sample appearance changed from transparent to turbid or turbid to transparent-based on visual observation-was determined. The phase boundary was marked in the pseudo-ternary phase diagrams using the Axio Vision Rel 4.8 software.

The potential formulations of the microemulsion were selected to load xanthone. It has been reported that the drug should be loaded before complete formulation is reached in order to ensure the highest entrapment efficiency [17]. Xanthone was therefore initially added in the mixture of oils and Smix. Finally, water was added to get the spontaneous complete formation of the microemulsion.

Carbopol aqua SF-1 and carbopol ETD 2020 were chosen as the gelling agents to prepare the xanthone-loaded microemulsion-based gel. The mixture of oil-Smix was mixed with the dispersion of the gelling agent in water. The dispersion was adjusted for $\mathrm{pH}$ to be 7.4 by TEA to form a viscous gel.

Physicochemical characterization of xanthone-loaded microemulsion and xanthone-loaded microemulsion-based gel

The mean droplet size of the microemulsions was determined by photon correlation spectroscopy (PCS) consisting of computerized auto-titrate (Nano ZS90, Malvern Instruments, UK) at a fixed angle of $173^{\circ}$. The droplet sizes were calculated by the dynamic light scattering (DLS) software. The microemulsion was subjected to $\mathrm{pH}$ evaluation using a digital $\mathrm{pH}$ meter (Metrohm 691). The viscosity of the microemulsion-based gel was determined using a Brookfield $\mathrm{R} / \mathrm{S}$-CPS rheometer. The data were calculated by using the Brookfield Rheo 2000 software. The viscosity measurements were obtained using a P25 DIN measuring system and it was in the controlled shear rate (CSR) mode.

\section{In vitro release}

An aliquot of $1 \mathrm{~g}$ of xanthone-loaded microemulsion and xanthoneloaded microemulsion-based gel in a pre-swollen dialysis bag (Cellu Sep ${ }^{\circledR}$ Nominal T1, Molecular Weight Cutoff 3,500 Da, Membrane Filtration Products, Inc.) was placed into $100 \mathrm{ml}$ of 50\% v/v Dioxane of Phosphate Buffer (pH 7.4) at $37^{\circ} \mathrm{C}$ for $10 \mathrm{~d}$ with gentle stirring at $200 \mathrm{rpm}$. A volume of $5 \mathrm{ml}$ of the receiving medium was withdrawn in differing time periods and the volume was adjusted by the fresh medium. The amount of xanthone in the various samples was measured using HPLC analysis, as previously described.

\section{Stability test}

To evaluate the physical stability, xanthone-loaded microemulsion and microemulsion-based gel were stored at various storage conditions (A: room temperature, B: $4{ }^{\circ} \mathrm{C}, \mathrm{C}: 45{ }^{\circ} \mathrm{C}$, and $\mathrm{D}$ : temperature cycle $4{ }^{\circ} \mathrm{C}[48 \mathrm{~h}]$ to $45^{\circ} \mathrm{C}[48 \mathrm{~h}]$ ) for a period of $2 \mathrm{mo}$. The clear, transparent, and isotropic microemulsion was visually examined.

\section{Antioxidant activity assays}

\section{ABTS assay}

The ability of the agents to scavenge 2,2'-azin-obis-(3ethylbenzothiazoline-6-sulfonic acid) or ABTS free radicals was determined in the same manner as described by Tachakittirungrod et al. [18]. The reaction between potassium persulfate $\left(\mathrm{K}_{2} \mathrm{~S}_{2} \mathrm{O}_{8}\right)$ and ABTS in water generated ABTS radical cations, with maximum absorbance at $750 \mathrm{~nm}$. The ABTS free radical solution was stored in the dark for $12 \mathrm{~h}$ and diluted to an absorbance of $0.7 \pm 0.2$ at $750 \mathrm{~nm}$ before using. The reaction between the ABTS free radical solution and the tested samples was made to occur in the dark for 5 min and the absorbance of the resulting mixture was measured by a microtiter plate reader. The antioxidant activity of the tested samples is expressed as a trolox equivalent antioxidant capacity (TEAC) value, using trolox for calibration.

\section{FRAP assay}

The antioxidant activity was also evaluated by ferric reducing antioxidant power or FRAP assay which represents the reducing power of the tested samples, as described previously [19]. The FRAP reagent was generated by mixing TPTZ with $\mathrm{FeCl}_{3}$ solution in acetate buffer. The FRAP reagent was added to the tested samples. The absorbance of the mixture was measured using a microtiter plate reader after keeping the reaction mixture for $5 \mathrm{~min}$. The antioxidant potential is expressed as an equivalent concentration (EC) value, using ferrous sulfate for calibration. 


\section{RESULTS AND DISCUSSION}

\section{Solubility test of xanthone}

The solubility of xanthone in different kinds of surfactants, cosurfactants and oils is shown in fig. 2. The results show that Capryol $90(58.0 \pm 3.4 \mathrm{mg} / \mathrm{ml})$ demonstrated better solubilizing capacity than other oils. While, the solubility of xanthone in Making oil was $19.3 \pm 0.3 \mathrm{mg} / \mathrm{ml}$, which is higher than in water (by about 20 times). Regarding the solubility of xanthone in surfactants, it was found that tween $80(52.2 \pm 0.1 \mathrm{mg} / \mathrm{ml})$ offered higher solubility than span 80 $(27.3 \pm 1.6 \mathrm{mg} / \mathrm{ml})$. Ethanol $(126.7 \pm 3.9 \mathrm{mg} / \mathrm{ml})$ and propylene glycol
$(82.6 \pm 4.4 \mathrm{mg} / \mathrm{ml})$ had slightly higher solubilizing ability than the surfactants. The highest solubilizing capacity was obtained from transcutol, whose solubility values corresponded with $142.6 \pm 0.8$ $\mathrm{mg} / \mathrm{ml}$. Transcutol is used in different kinds of pharmaceutical formulations due to its ability to effectively enhance the effect of skin penetration and its excellent solubilizing ability [12]. Based on their high solubilizing capacity, transcultol, tween 80 and ethanol or propylene glycol were selected as the solubilizing agent, the surfactant and the co-surfactants, respectively. Similarly, Making oil in combination with Capryol 90 was chosen in the oil phase by considering the desired solubility of xanthone.

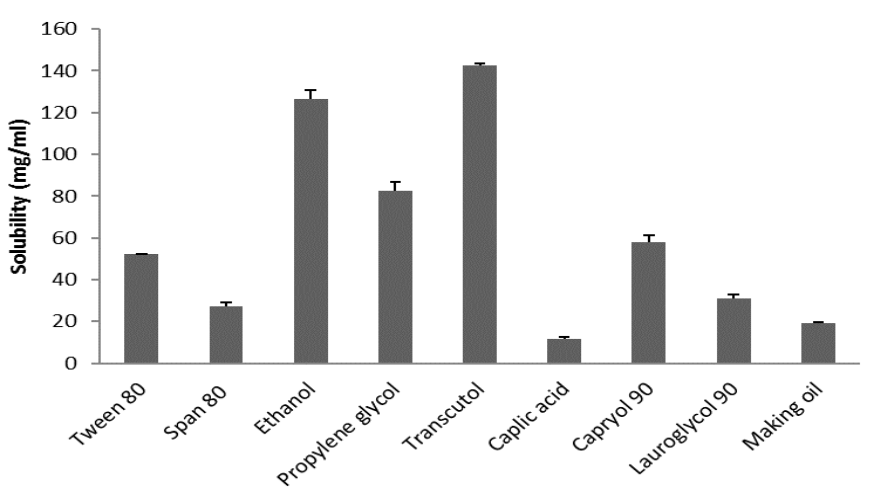

Fig. 2: The solubility of xanthone in various vehicles at room temperature. Error bars indicate mean \pm SD of triplicate experiments
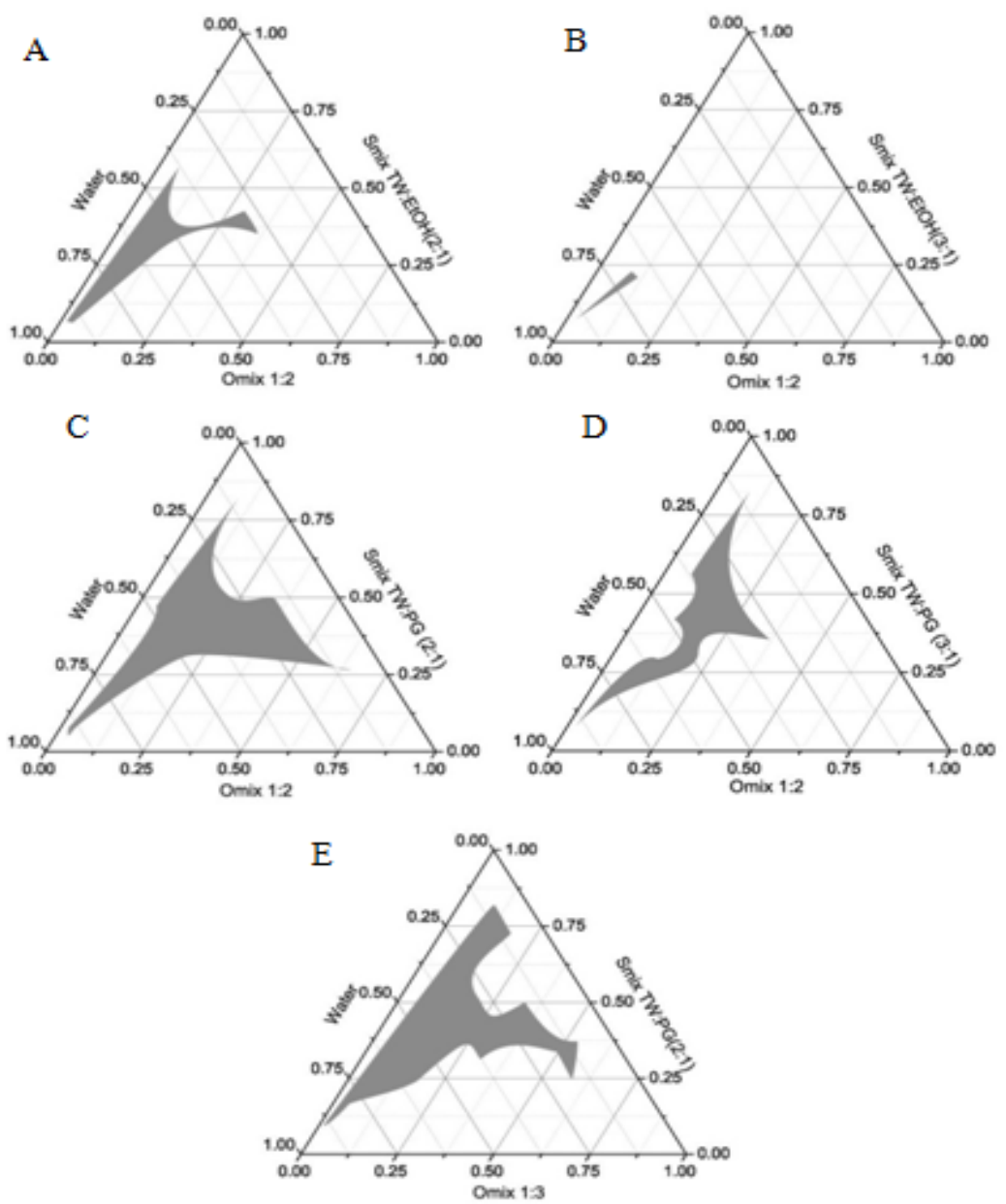

Fig. 3: The pseudo-ternary phase diagrams of the microemulsion region (black region) containing water, oil (Making oil and capryol 90 in the ratio of 1:2), and Smix of tween 80 and ethanol in the ratio of 2:1 (A); water, oil (Making oil and capryol 90 in ratio of 1:2), and Smix of tween 80 and ethanol in the ratio of 3:1 (B); water, oil (Making oil and capryol 90 in the ratio of 1:2), and Smix of tween 80 and propylene glycol in the ratio of 2:1 (C); water, oil (Making oil and capryol 90 in the ratio of 1:2), and Smix of tween 80 and propylene glycol in the ratio of 3:1 (D); water, oil (Making oil and capryol 90 in the ratio of 1:3), and Smix of tween 80 and propylene glycol in the ratio of 2:1 (E) 
Preparation and characterization of xanthone-loaded microemulsion and xanthone-loaded microemulsion-based gel

Pseudo-ternary phase diagrams containing different weight ratios of water, oil (Making oil and capryol 90), and Smix (tween 80 and ethanol [fig. 3A-B] or tween 80 and propylene glycol [fig. 3C-E]) were constructed by the simple titration method and reported in fig. 3 . The dark region in the fig. is the microemulsion region. Whereas, the white region is the opaque, or cloudy, region. The lowest microemulsion region can be found in diagram 3B. While, the highest microemulsion region obtained is in diagram 3E, followed by diagrams 3C and 3D, respectively. The result shows that the ternary diagram of the Smix of tween 80 and propylene glycol had a wider microemulsion region than that of the Smix of tween 80 and ethanol. Moreover, the size of the microemulsion region was affected by the ratio of surfactant to co-surfactant in the order of $2: 1>3: 1$ in agreement with a previous report [20]. The co-surfactants penetrate into the interface between the oil and the water phases, resulting in a decrease in the surface tension, an increase in the flexibility of the surfactant film, and an increase in the water solubility [20,21]. Even oils play an important role in microemulsion due to their effects on the microemulsion area, drug-loading efficiency, and lymphatic transport [22]. In this study, the combined use of oils-in a variety of ratios-yielded a lower correlation with the microemulsion area than that obtained with the combined use of the surfactant and the co- surfactant. Therefore, the suitable compositions and concentrations of compositions to form the microemulsion were selected from the pseudo-ternary phase diagrams $3 \mathrm{E}$ and $3 \mathrm{C}$, considering their wide area of microemulsion.

Table 1 shows the compositions of drug-free microemulsion (F1-4) and $0.5 \% \mathrm{w} / \mathrm{w}$ xanthone-incorporated microemulsion (F5-8). The Making microemulsions were homogenous, clear, isotropic, and transparent systems. Whereas, the xanthone-entrapped microemulsions were orange and transparent without the phase separation of the different formulations after centrifugation at $10 \mathrm{~kg}$ at room temperature for $30 \mathrm{~min}$, resulting from the successful loading of xanthone into the microemulsion (as shown in fig. 4).

The average droplet size of the drug-free microemulsion was in the range of $64.1 \pm 11.6 \mathrm{~nm}$ to $74.2 \pm 8.2 \mathrm{~nm}$ and the $\mathrm{pH}$ values were in the range of $5.50 \pm 0.06$ to $6.54 \pm 0.22$. Higher mean droplet size was found in the xanthone-loaded microemulsion $(108.93 \pm 2.57 \mathrm{~nm}$ to $133.63 \pm 0.55 \mathrm{~nm}$ ). It should be noted that the higher size was related to the presence of xanthone (active compound) as well as transcutol (solubilizing agent). This is probably due to the interaction of the loaded active compound or solubilizing agent with the surfactant layer. However, the average size of the xanthone-incorporated microemulsion was less than $150 \mathrm{~nm}$, which is a satisfactory result for the microemulsion systems $[23,24]$.

Table 1: Formulations and sizes of drug-free microemulsion and xanthone-loaded microemulsions

\begin{tabular}{|c|c|c|c|c|c|c|c|c|}
\hline \multirow[t]{2}{*}{ Formulation } & \multicolumn{6}{|c|}{ Composition (\%w/w) } & \multicolumn{2}{|r|}{ Size (nm) } \\
\hline & Making oil & Capryol 90 & Twe & & PG & Water & Xanthone & Transcutol \\
\hline 1 & 6.7 & 13.3 & 24.2 & 12.0 & 43.8 & - & - & $64.1 \pm 11.6$ \\
\hline 2 & 6.7 & 13.3 & 27.2 & 9.1 & 43.8 & - & - & $72.5 \pm 16.5$ \\
\hline 3 & 5.0 & 15.0 & 24.2 & 12.0 & 43.8 & - & - & $74.2 \pm 8.2$ \\
\hline 4 & 5.0 & 15.0 & 27.2 & 9.1 & 43.8 & - & - & $65.4 \pm 4.1$ \\
\hline 5 & 6.7 & 13.3 & 24.2 & 12.0 & 39.3 & 0.5 & 4 & $133.63 \pm 0.55$ \\
\hline 6 & 6.7 & 13.3 & 27.2 & 9.1 & 39.3 & 0.5 & 4 & $108.93 \pm 2.57$ \\
\hline 7 & 5.0 & 15.0 & 24.2 & 12.0 & 39.3 & 0.5 & 4 & $114.56 \pm 8.91$ \\
\hline 8 & 5.0 & 15.0 & 27.2 & 9.1 & 39.3 & 0.5 & 4 & $114.26 \pm 15.38$ \\
\hline
\end{tabular}

Note: Size values are expressed as mean $\pm S D, n=3$

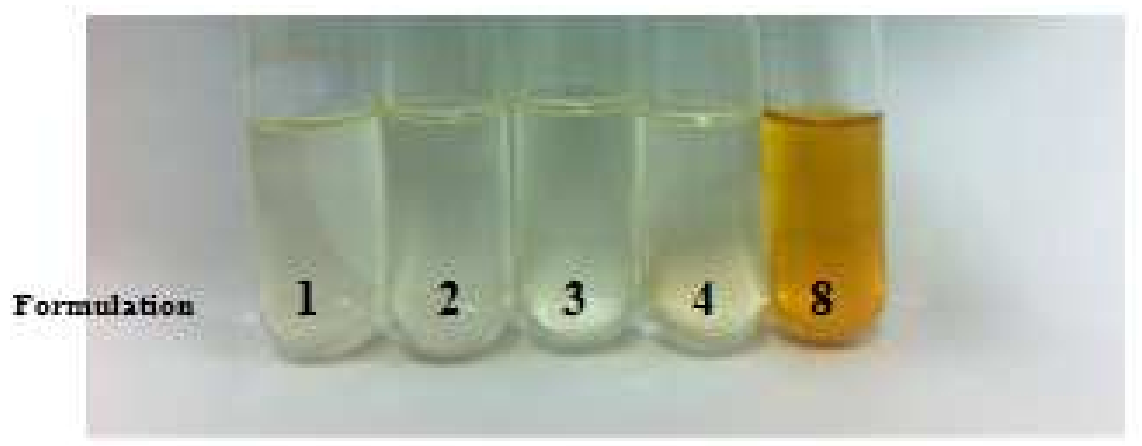

Fig. 4: Microemulsion (Formulations 1-4) and microemulsion loaded with xanthone at a concentration of 0.5\% (Formulation 8)

Table 2 demonstrates that the viscosity of the xanthone-loaded microemulsion-based gel using carbopol aqua SF-1 at a concentration of $15 \%$ was about the same as that using carbopol ETD 2020 at a concentration of $1.5 \%$ with Eta values around 24 Pas. As expected, the Eta values of the xanthone-loaded microemulsion- based gel decreased as the concentration of the gelling agent was reduced. The flow patterns of the xanthone-loaded microemulsionbased gel using carbopol aqua SF-1 and that using carbopol ETD 2020 were plastic characteristics and plastic characteristics with thixotropic features, respectively (as shown in fig. 5).

Table 2: Viscosity values of formulations of xanthone-loaded microemulsion-based gel

\begin{tabular}{lll}
\hline Gelling agent & Composition $(\% \mathbf{w} / \mathbf{w})$ & Viscosity, Eta $($ Pas) \\
\hline Carbopol Aqua SF-1 & 10 & $11.97 \pm 1.72$ \\
Carbopol Aqua SF-1 & 15 & $24.46 \pm 1.12$ \\
Carbopol ETD 2020 & 0.5 & $8.25 \pm 0.87$ \\
Carbopol ETD 2020 & 1.0 & $18.83 \pm 0.70$ \\
Carbopol ETD 2020 & 1.5 & $23.09 \pm 0.79$ \\
\hline
\end{tabular}

Note: Viscosity values are expressed as mean $\pm \mathrm{SD}, \mathrm{n}=3$ 

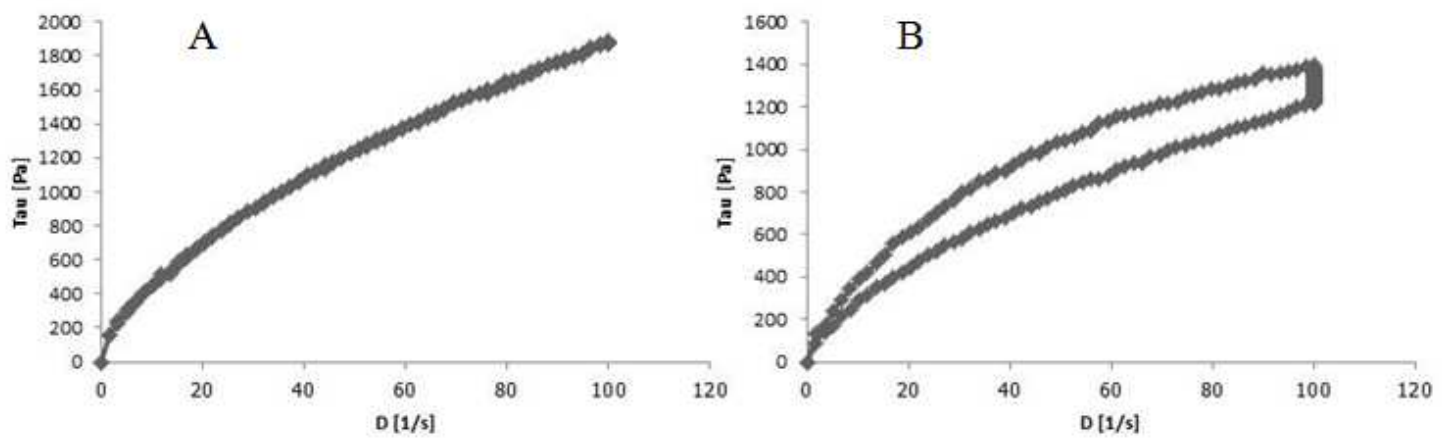

Fig. 5: The rheological profile of xanthone-loaded microemulsion-based gel using $15 \%$ carbopol aqua SF-1 (A) and $1 \%$ carbopol ETD 2020 (B) as the gelling agent

\section{In vitro release}

The ability of microemulsion and microemulsion-based gel to release xanthone was determined by the in vitro release study. Fig. 6 shows that rapid release of xanthone from microemulsion (around $54 \%$; without the initial burst release) occurred in $22 \mathrm{~h}$ and that it reached a plateau (almost $100 \%$ ) in the following $48 \mathrm{~h}$. On the other hand, $19 \%$ of xanthone was released from the microemulsion-based gel at $22 \mathrm{~h}$. The xanthone of the microemulsion-based gel was subsequently released for up to $3 \mathrm{~d}(\sim 80 \%)$ with a plateau formation. The slow release of xanthone from the microemulsionbased gel confirms that there exists the capacity for partitioning between the oil and the aqueous phases and that the controlling of the drug release is affected by the viscosity of the gel $[25,26]$.

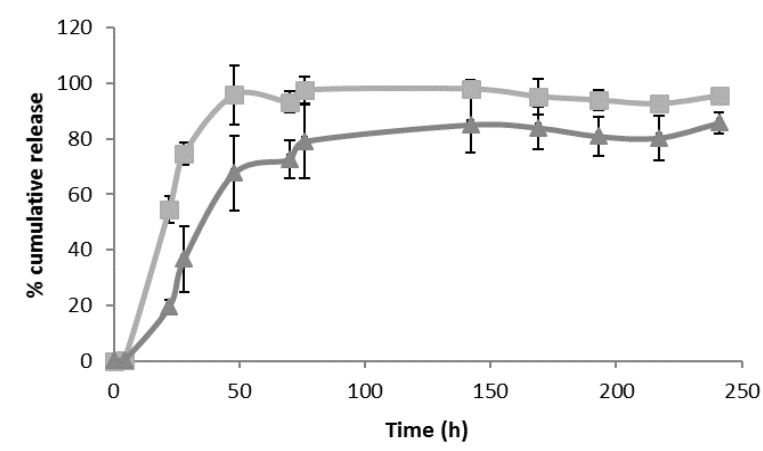

Fig. 6: The release of xanthone from microemulsion ( $\square)$ and microemulsion-based gel $(\Delta)$, pH 7.4, $37^{\circ} \mathrm{C}$. Error bars indicate mean $\pm S D$ of triplicate experiments

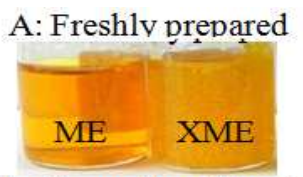

B: XM after 2 months of incubation

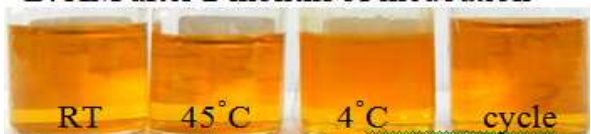

$\mathrm{C}$ : XMG after 2 months of incubation

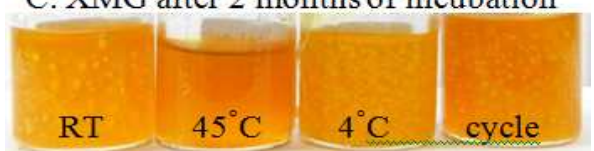

Fig. 7: The physical appearance of freshly prepared and storedfor-2-months xanthone-loaded Making oil microemulsion (XM) and xanthone-loaded Making oil microemulsion-based gel (XMG) at various storage conditions (room temperature [RT], $45^{\circ} \mathrm{C}, 4^{\circ} \mathrm{C}$, and temperature cycle, respectively)

\section{Stability test}

Fig. 7 reveals that the xanthone-loaded microemulsion and the microemulsion-based gel remained clear and transparent without any color change after being stored at room temperature, $45^{\circ} \mathrm{C}$, and under temperature cycle conditions for $60 \mathrm{~d}$. However, the sample of xanthone-loaded microemulsion stored at $4{ }^{\circ} \mathrm{C}$ was observed to have precipitated after $20 \mathrm{~d}$. This occurred probably due to the lower solubility capacity of xanthone at low temperatures. More stability was offered by xanthone-loaded microemulsion-based gel when kept in a refrigerator $\left(4^{\circ} \mathrm{C}\right)$ for 2 mo. This can be ascribed to the higher stability of xanthone-loaded microemulsion-based gel as compared to xanthone-loaded microemulsion.

\section{Antioxidant activity assays}

Fig. 8 presents the result of the ABTS assay. The free radical scavenging activity of xanthone-loaded microemulsion was around the same as that of xanthone-loaded microemulsion-based gel, with TEAC values of $9.8 \mathrm{mmol} / \mathrm{mg}$ and $9.4 \mathrm{mmol} / \mathrm{mg}$, respectively. After $30 \mathrm{~d}$ of storage, the free radical scavenging capacities of the loaded microemulsions underwent a small decrease in comparison with the freshly prepared samples. For the FRAP assay, the EC value of the xanthone-loaded microemulsion was $14.8 \mathrm{mmol} / \mathrm{mg}$, while the EC value of the xanthone-loaded microemulsion-based gel was 18.5 $\mathrm{mmol} / \mathrm{mg}$ (as shown in fig. 9). After extended storage, the reducing capacities of both xanthone-loaded microemulsion and xanthoneloaded microemulsion-based gel were not significantly different from the reducing capacity of freshly prepared samples. The results of the FRAP assay with regard to the reducing activity were in accordance with those of the ABTS assay regarding the free radical scavenging activity, which indicates that xanthone continued to have high antioxidant activity after being incorporated into microemulsion, or microemulsion-based gel, even under extended storage conditions.

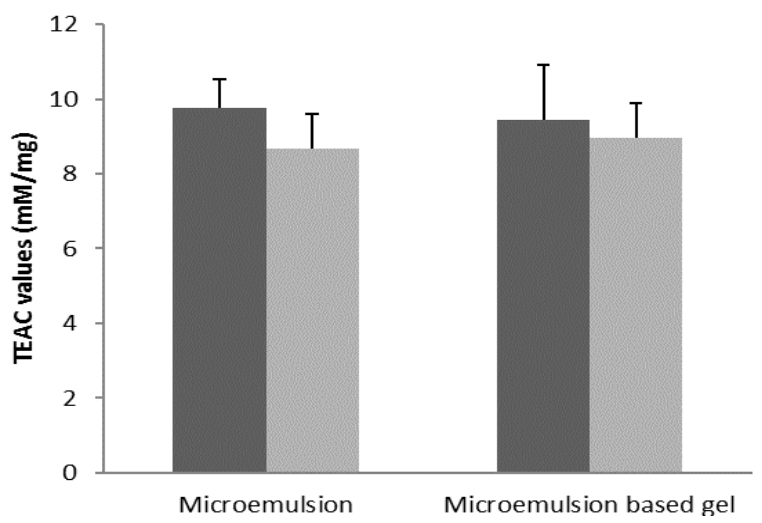

Fig. 8: The antioxidant activity of freshly prepared (a) and stored-for-3-months ( $\square$ ) xanthone-loaded microemulsion and xanthone-loaded microemulsion-based gel using the ABTS assay. Error bars indicate mean $\pm S D$ of triplicate experiments 


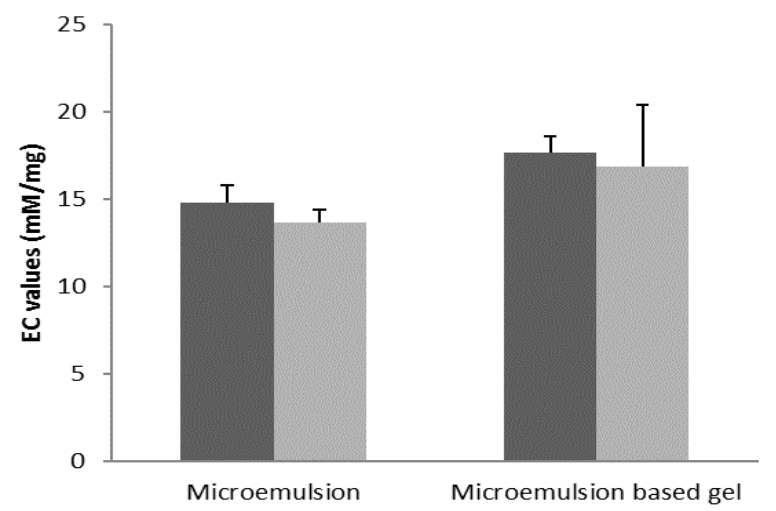

Fig. 9: The antioxidant activity of freshly prepared ( $\square$ ) and stored-for-3-months ( $\square$ ) xanthone-loaded microemulsion and xanthone-loaded microemulsion-based gel using the FRAP assay. Error bars indicate mean $\pm S D$ of triplicate experiments

\section{CONCLUSION}

GC analysis showed that Making seed oil mainly consists of linoleic acid and oleic acid. The stable xanthone-loaded Making microemulsion and microemulsion-based gel were successfully prepared and characterized by mean droplet size, $\mathrm{pH}$, and viscosity. An improvement in the aqueous solubility of xanthone was achieved after it was loaded into the Making microemulsion. Slow release of xanthone and higher stability were observed in xanthone-loaded microemulsion-based gel in comparison with xanthone-loaded microemulsion. Even under the condition of extended storage, potential for high antioxidant activity was observed in both xanthone-loaded Making microemulsion and microemulsion-based gel. Therefore, it can be safely concluded that Making microemulsion has great potential to be an effective vehicle for delivering xanthone, an antioxidant agent.

\section{ACKNOWLEDGMENT}

The authors would like to acknowledge the financial support provided by Plant Genetic Conservation Project under the Royal Initiative of Her Royal Highness Princess Maha Chakri Sirindhorn.

\section{CONFLICT OF INTERESTS}

There are no conflicts of interest to declare

\section{REFERENCES}

1. Ibrahim MY, Hashim NM, Mariod AA, Mohan S, Abdulla MA, Abdelwahab SI, et al. $\alpha$-Mangostin from Garcinia mangostana Linn: an updated review of its pharmacological properties. Arabian J Chem 2016;9:317-29.

2. Nugrahaeni DK, Hadisaputro S, Suwondo A, Dharmana E. The effect of alpha-mangostin in balancing the ratio of cytokines pro-and antiinflammation-gamma (INF- $\gamma /$ IL-10) and severity of the disease in mice infected with Mycobacterium tuberculosis multidrug-resistant. Asian J Pharm Clin Res 2016;9 Suppl 3:273-7.

3. Rahmayanti FR, Suniarti DF, Mas'ud ZA, Bachtiar BM, Wimardhani YS, Subita GP. Ethyl acetate fraction of Garcinia mangostana-Linn pericarp extract: anti-C. Albicans and epithelial cytotoxicity. Asian J Pharm Clin Res 2016;9:357-60.

4. Chen LG, Yang LL, Wang CC. Anti-inflammatory activity of mangostins from Garcinia mangostana. Food Chem Toxicol 2008;46:688-93.

5. Mahabusarakam W, Proudfoot J, Taylor W, Croft K. Inhibition of lipoprotein oxidation by prenylated xanthones derived from mangostin. Free Radical Res 2000;33:643-59.

6. Pedraza-Chaverri J, Cardenas-Rodriguez N, Orozco-Ibarra M, Perez-Rojas JM. Medicinal properties of mangosteen (Garcinia mangostana). Food Chem Toxicol 2008;46:3227-39.

7. Sakagami $Y$, Iinuma $M$, Piyasena KG, Dharmaratne HR. Antibacterial activity of [alpha]-mangostin against vancomycin resistant Enterococci (VRE) and synergism with antibiotics. Phytomedicine 2005;12:203-8.

8. Edwards J, Pappa G, Torok M, Fowler A, Bausch J. [alpha]Mangostin: Developmental toxicity in vitro and in screening tests. Toxicol Lett 2009;189:S144.

9. Khonkarn R, Mankhetkorn S, Talelli M, Hennink WE, Okonogi S. Cytostatic effect of xanthone-loaded mPEG-b-p(HPMAm-Lac2) micelles towards doxorubicin sensitive and resistant cancer cells. Colloids Surf B 2012;94:266-73.

10. Dai J, Kim SM, Shin IS, Kim JD, Lee HY, Shin WC, Kim JC. Preparation and stability of fucoxanthin-loaded microemulsions. J Ind Eng Chem 2014;20:2103-10.

11. Sahooa S, Pania NR, Sahoob SK. Microemulsion based topical hydrogel of sertaconazole: formulation, characterization and evaluation. Colloids Surf B 2014;120:193-9.

12. Censi R, Martena V, Hoti E, Malaj L, Martino PD. Permeation and skin retention of quercetin from microemulsions containing Transcutol@ P. Drug Dev Ind Pharm 2012;38:112833.

13. Pooma R. Rare plants of Thailand. Office of Natural Resources and Environmental Policy and Planning, Bangkok; 2008. p. 221.

14. Schreitera J, Gerhard L, Joachim H, Josef M. Hodgsonia heteroclita (Roxb.) Hook. f. and Thomson (Cucurbitaceae)-a neglected oil plant in Southwest China. Conference on International Agricultural Research for Development. University of Kassel-Witzenhausen and University of Göttingen; 2007.

15. Asai F, Tosa $\mathrm{H}$, Tanaka T, Iinuma M. A xanthone from pericarbs of Garcinia mangostana. Phytochemistry 1995;39:943-4.

16. Carstens MG, Jong PHJLF, Nostrum CF, Kemmink J, Verrijk R, Leede LGJ, Crommelin DJA, et al. The effect of core composition in biodegradable oligomeric micelles as taxane formulations. Eur J Pharm Biopharm 2008;68:596-606.

17. Cavalcanti AL, Reis MY, Silva GC, Ramalho ÍM, Guimarães GP, Silva JA, Saraiva KL, et al. Microemulsion for topical application of pentoxifylline: in vitro release and in vivo evaluation. Int J Pharm 2016;506:351-60.

18. Tachakittirungrod S, Okonogi S, Chowwanapoonpohn S. Study on antioxidant activity of certain plants in Thailand: mechanism of antioxidant action of guava leaf extract. Food Chem 2007;103:381-8.

19. Okonogi S, Duangrat C, Anuchapreeda S, Tachakittirungrod S, Chowwanapoonpohn S. Comparison of antioxidant capacities and cytotoxicities of certain fruit peels. Food Chem 2007;103:839-46.

20. Patel MR, Patel RB, Parikh JR, Patel BG. Novel microemulsionbased gel formulation of tazarotene for therapy of acne. Pharm Dev Technol 2015;3:1-12.

21. Rhee YS, Choi JG, Park ES, Chi SC. Transdermal delivery of ketoprofen using microemulsions. Int J Pharm 2001;228:161-70.

22. Gershanik T, Benita S. Self-dispersing lipid formulations for improving oral absorption of lipophilic drugs. Eur J Pharm Biopharm 2000;50:179-88.

23. Tenjara S. Microemulsion: an overview and pharmaceutical applications. Crit Rev Ther Drug Carrier Syst 1999;16:461-521.

24. Bergonzi MC, Hamdouch R, Mazzacuva F, Isacchi B, Bilia AR. Optimization, characterization and in vitro evaluation of curcumin microemulsions. LWT-Food Sci Technol 2014; 59:148-55.

25. Ho HO, Hsiao CC, Sheu MT. Preparation of microemulsions using polyglycerol fatty acid esters as surfactant for the delivery of protein drugs. J Pharm Sci 1996;85:138-43.

26. Panapisal V, Charoensri S, Tantituvanont A. Formulation of microemulsion systems for dermal delivery of silymarin. AAPS PharmSciTech 2012;13:389-99.

How to cite this article

- Sunee Chansakaow, Panee Sirisa-Ard, Ruttiros Khonkarn. Preparation, characterization and antioxidant activity of xanthone-loaded Making (Hodgsonia heteroclita) microemulsions. Int J Pharm Pharm Sci 2017;9(3):262-267. 